\title{
Physical Activity \\ as a Sociological Phenomenon
}

\author{
Aleš Sekot \\ Masaryk University, Brno, Czech Republic
}

ABSTRACT

\begin{abstract}
We are living in a time when society, culture and science have become increasingly aware of the great importance of sport not only as a part of mass culture, but broadly understood, for individual and social health and wellbeing. Physical activity of people plays an increasingly more important role in scientific interest regarding way of life found in contemporary society; it is a crucial factor in the process of officiating the level of healthy and active lifestyles, quality of life, and health in general. An indispensable role of physical activity in the course of human life is also confirmed, both permanently and scientifically, in the context of obesity prevention.

The development of a sedentary lifestyle is the result of a socialization process that is developed at youth and continued into adulthood, and leads to physical inactivity. At the present we face in our cultural settings an apparent trend: People are becoming more and more individualized, losing the beneficial impact of community activities, involved in passive way of life that lacks a proper level of physical activities and active sport. The phenomenon of physical activity has also been considered from the perspective of the Project EURO-PREVOB, highlighting built environmental aspects of ways of life.
\end{abstract}

KEYWORDS $\quad$ physical activity, sport, health, quality of life, socialization, built environment

\section{General situation}

It was not that long ago that sport was absent from the imaginary and cultural practices of the majority of people. Although it is true that traditional games were typical among popular social classes, they never had the reach that modern sport has acquired among us today. Thanks to social recognition within educational or associative bodies and the development of the welfare state, modern sports (track and field, cycling, rowing, basketball, etc.) have become a generalized cultural practice since the second half of the $20^{\text {th }}$ century. The practice of sport stopped being the privilege of a minority and became an objective that needed to be stimulated and maintained with public spending and incorporated into the lifestyles of the general population: sport as part of our lifestyles is seen positively by the majority of the population. In this context, sport also responds to the paradoxes of modernity: environmental consciousness versus increased environmental degradation; advances in innovation and knowledge in the health field versus the emergence and spread of new diseases; concerns for our physical and psychological health versus increases in sedentarism and obesity, etc. In this context one is reminded that concern for health and the analysis of health are as old as humanity. In the broader context of physical activity the promotion of health does not only correspond to health 
authorities, nor does it exclusively belong in the area of health assistance or services. It is necessary to aim for a more comprehensive vision of health where health and an active lifestyle are perceived as a state of physical, mental and social well-being. The state of self-perceived health can be defined as the perception that individuals have of their own health, a more global dimension that constitutes a more comprehensive state of well-being.

Physical activity, as an indispensable agent of healthy lifestyle, is understood in a broad sense as covering both sporting practices as well as other types of actions (walking and the tasks of daily life). It is activity not requiring a priori such intense and regular effort as sport, but does require physical work related in one form or another with health. It is generally considered to be necessary to do physical activities and sport three to five days a week, at a low to moderate intensity, with a duration of between 20 and 60 minutes. The American College of Sports Medicine says that it is necessary to do at least 30 minutes of low or moderate physical activity most days of the week to obtain health benefits (USDHHS 1996). These parameters, however, depend on the type of activity and other factors. The key to considering physical activity as healthy is the expenditure of energy. A measure of the intensity of physical activity has been set at 10000 steps per day, which for an older person would mean a physical activity of 30 minutes of aerobic exercise and which implies the use of large muscle groups and entails stretching and minor strength exercises.

On the other hand, a "purely sedentary lifestyle" is characterized by not taking walks in regular manner, not doing sport, and spending the majority of the day sitting - essentially the polar opposite of an active lifestyle advocated by health authorities as an element beneficial for health. "Active lifestyle" reflects to practice sport, walking, and non-sedentary work during working day. In short, the variables "walking or taking walks", "doing sport" and "activities of daily life" are considered to be the elements that constitute the levels of physical activity and sedentary lifestyle. In this context, walking and taking walks gains growing importance among seniors, as both are another element of physical activity. Both also significantly influence the perceived state of health of the population, though with less importance than sport: it is not unusual to find, across both urban and rural landscapes, older people walking in small groups for their health along what is now popularly known as the "cholesterol route". To summarize this phenomenon, sport and health professionals, through scientific evidence contributed by many studies, insist on the practice of intentional physical activity under specific parameters of duration frequency and intensity as an element of health.

Physical activity as an integral part of an active lifestyle reflects a specific aspect of the phenomenon of quality of life as well. Quality of life is a relatively new concept which, since the 1970s, emerged with the intention of extending the understanding of two concepts commonly considered in the objectives of social policy: a concept with strongly economic implications, "welfare", and another with psychosocial implications, "well-being". Beginning in the 1980s, the concept of "quality of life" gained particular importance in the design of all types of policies, programs and social projects - in healthcare, the social environment, etc. - as they specifically raised the "improvement of quality of life" as an objective. Policies and programs to promote sport or physical activity were also expressed in this way, in international forums, for example, within the relevant materials of World Health Organization (WHO). Given the importance of health and quality of life in sport policies, physical activity and sport is highlighted as an important contributor to the well-being and quality of life of a population. From the sociological point of view, it is accented that physical activity, in its distinct forms, seems to lead to greater well-being in all age groups, although fundamentally among young people and seniors. It is scientifically confirmed that walking as well as practicing sport and physical activity are related to well-being (Andersen et al. 2007, Frömel et al. 2004, McElroy 2002). When all forms of physical activity are taken into account, sport becomes the factor of greatest importace which measure the active lifestyle in the context of the quality of life of a population: people that did more physical activity and did sport reported feeling greater well-being (Sánchez, Estrada 2009, p. 93, 100). Quality of life is a broader concept than that of health, as it includes the possibility of personal realization in all dimensions of life, health being a basic condition 
amongst these. Quality of life reflects the capacity to do what one wants, because the body is capable of responding to the desires of the mind, and this is adapting to the normal possibilities of the body. Quality of life permits the enjoyment of the physical environment and a network of social relations; it is having the independence that comes from good health.

Quality of life in relation to sport and health concepts reflects the fact that the practice of sport will improve health, and better health will reflect a better quality of life. Also, the influence of sport on psychological well-being is evident because physical activity stimulates the production of hormones that improve psychological well-being, so that sport also has a positive influence on psychological illnesses, improving the psychomotor capacity of the individual. Consequently, sport increases the personal autonomy perceived by the subject, which positively influences personal mood, highlights better social relations which avoids isolation, and provides greater security. Physical activity is not only boosted by the endorphins that it generates but also by the improvements in social life that practitioners of sport get from its collective activities (Sánchez, Estrada 2009, pp. 149-156). In short: the most widespread opinion among the sport experts is that the practice of sport not only has immediate benefits, but also an important social component. Sport betters the diet, improves an individual's physical shape, and supports healthy sleep. Sport makes people respectful, more selfdisciplined and responsible, increases their motivation, and distances them from deviant behaviour. Sport is benefical at all ages, and improvements in health and in the quality of life are evident in all of them, especially among young people and seniors. For young people sport is an integral and indispensable part of complex socialization; for seniors it has both therapeutic and social impact. The specific situation found in Czech society - a growing proportion of seniors - must be reflected in growing support for sport for old people. Among the benefits of sporting activities of seniors is a pointed improvement in self-esteem and self-image; a reduction in the risk of depression and the relief of existing depression; a decrease in pain and increase in quality of life; the reinforcement of healthy diets and good health in general; the modification of musculoskeletal composition; the link of sport with greater intellectual capacity; and the prevention of deterioration associated with age and hypokinetic pathologies.

It is evident that sport and quality of life have a reciprocial relationship. We must take into account that the practice of sport requires the availability of free time, some basic conditions of health, the existence of installations or spaces for doing sport, and sometimes all of this is related to enjoying a sufficient comfortable economic situation (Sekot 2006, Slepička, Slepičková 2002).

Today, doing sport is synonymous with being in shape, improving our health and relating with others, and improving our personal well-being. But at the same time we face the growing existence of new forms of leisure, many tied with the use of new technologies, mostly called "digital entertainment" (surfing the web, chatting, sending SMSs), and to new patterns of consumption (shopping in shopping malls or visiting aqua parks). In our cultural settings, the physical character of leisure is mostly characterized by activities such as "going for walks", "doing sport", "nature activities" and "travelling". But almost all sociological data in the global context reflect an important asymmetry between interest in sport and the practice of sport.

The growing technological, economic, cultural, biomedical and social developments of European societies have produced a high level of comfortable living for a very large segment of the population. The transformation from an industrial society to an information society since the $1960 \mathrm{~s}-$ fuelled by large advances in computer technology - has caused "the great wave of change". Significant changes in the composition of the workforce has transferred the economic and the social roles of men and women, but also affected matters of health, attitudes to physical activities and sport (McElroy 2002).

Physical inactivity and obesity are comprehended as risks to both the health individual body and to the social body. Responding to such opinion, some scholars have begun to overcome our contemporary disquiet with obesity in particular and inactivity to a lesser extent (Evans 2003). 
Anyway, inactivity and obesity are complex phenomena regarded in general as risk factors, conveying their self-responsibility and self-control imperatives and deploying them so as to accomplish the normative "healthy citizen".

Professionals in the health sciences have demonstrated, through epidemiological and longitudinal studies, the importance of physical activity and sport in the maintenance of our health and quality of life (Andersen et al. 2007, Evans 2003, MElroy 2002, Sallis, Owen 1999). In such a context, we must accent that sport and physical exercise produce physical, biological, psychological and social benefits, and are important at both a therapeutic and preventative level. Regarding physical benefits, sport activities improve motor functioning and the musculoskeletal and immune systems; positively activate the hormonal system and balance the body through homeostasis and the lymph of the blood, thus preventing the appearance of lesions and illnesses. At the psychological level, sport, exercise and physical activities stimulate the production of hormones that improve personal well-being by increasing the psychomotor capacity of the individual and with this, the sensation of personal autonomy, which positively affects the mood, something necessary to face mental disorders and to strengthen emotional control. At the social level, sporting activities also help in improving social and individual skills such as assertiveness and self-esteem, and among groups at risk they aid in preventing problems of social deviancy (Sanchez, Estrada at al. 2009, pp. 11-12).

Physical inactivity is a major public health challenge in the developed world and is recognized as a global epidemic. Conventionally, sport and forms of physical activity such an aerobics, running or gym work have been the focus of efforts to increase a population's activity levels. It is not without interest that The Health Survey for England (HSE) measures activities such as gardening and housework, which are not traditionally considered physical activity. In England it was found that in the 10-year period between 1987 and 1996 participation in traditional types of sport and physical activity stagnated or fell in all groups; that fact reflects the many broad influences on physically active behaviour including intra-personal, social, environmental factors. These determinants vary across the life course (Sallis, Owen 1999). Regarding education and occupation, relevant sociological data from most resources confirm that the largest proportion of those whose practice sport are people from secondary or university studies and come mostly from mid-level management and executive backgrounds. The educational level - one of the principal mechanisms of the socialization of values and habits - increases the difference in numbers between those that have sedentary lifestyles and those that have active lifestyles.

From a similar perspective, it is evident that sport and physical activity is gaining significance in social, political and health policy. From the point of view of research into determinants of sport and physical activity participation, the tendency to adopt quantitative methods is observed. Respondents are usually asked about activity in five domains (Allender et al. 2006, p. 827):

1. Activity at work,

2. Activity at home (e.g. Housework, gardening, do-it-yourself maintenance),

3. Walks for a minimum of 15 minutes,

4. Sport activities,

5. Exercise activities.

Some organizations, such the U.S. Department of Health and Human Services (HHS) as well as the American College of Sports Medicine, point out that to obtain significant health benefits prom physical activity and sport, the activity must be done for at least 30 minutes almost every day of the week. As physical activity is vital to our health and quality of life, it is predictable that inactivity provokes negative effects. The problems associated with the lack of sporting activities raise major concerns for two specific sectors of the population: youth and seniors. Regarding youth: they represent a generation in which sedentary life styles have begun to consolidate. Increasingly, youth in many "affluent societies" consume too many high calorie foods and toxic substances. They are losing the habit of doing sport or exercising, and spend the majority of their time (including leisure) seated and mostly passive. Regarding the senior population: to maintain a good state of health during this stage of 
life also depends on doing exercise and sport. Inactivity leads to a progressive deterioration of health conditions. The health system is becoming more and more difficult and costly to treat illnesses associated with aging.

Relevant perspective to barriers to participation in sport and physical activity on a simple level include high cost, poor access to facilities, and unsafe environments. Though most likely not addressed, the generally manifest factor of human laziness plays "some" important role in the barriers to physical and sport activity too! To summarize the topic of general motivations and barriers to participation in physical and sportive activity, it could be concluded that fun, enjoyment and social support are more important predictors of participation than the perceived role of health benefits. Along with older groups, children see enjoyment and social interaction with peers as reasons to be physically active. In most cases, the role models for children and young adults are usually beautiful and slim - in the case of women - and muscular, in the case of men. The desire to be slender and to avoid being overweight and obese leads to an increased motivation to be physically active. But this model does not work strongly in older populations (Allender 2006, pp. 832-833).

People today lead very different lives than their parents and grandparents did. For the most part, our generation is more educated, better off financially, and geographically more mobile than our predecessors. And having the right weight, shape and being fit are important attributes in our culture: to be obese means to be personally and socially handicapped. Physical activity in combination with dieting has been acknowledged as a complete weight-loss strategy, and therefore one might expect people attempting to lose weight to be more willing to embrace a strategy that includes regular exercise.

In recent years the concept of "lifestyle" and "active lifestyle" have become the focus of attention of the biological and social sciences and of their often different system approaches. The reason for this is due to the fact that the active lifestyle is closely related to significant human values, people's duality of life and health status. Social demographic and psychological characteristics such as an age, gender, social and economical status, including his or her physical activities, all form part of the attributes of the lifestyle.

In noting some important determinants and correlates of physical activity among European youth, we present some topical empirical data (Telama et al. 2007, pp. 266-274):

1. Low sport participation of girls in Southern Europe,

2. Polarisation of physical activity of boys, reflecting at the same time both the increasing level of inactivity and number of vigorous sportive activities,

3. The decrease of age of beginners in sport,

4. Pre-school participation of children in organized sport,

5. Physical activity is seen as a means to prevent overweight at young age,

6. Overweight and obesity can be barriers of participation in physical activity,

7. Among boys, fitness and sport or athletic competence have been connected with a positive selfimage,

8. Among girls, fitness and sport or athletic competence have been connected mainly with attractiveness of body and self worth,

9. The influence of parents is more important for children's participation in organized sports than for physical activity in general,

10. Best friends are strong predictors of adolescents' physical activity,

11. Physical activity and sport participation is to a great extent a social activity,

12. Positive relations between the socioeconomic status of a family and a child's physical activity and sport participation,

13. Urban environment offers better access to different facilities and more possibilities to participate in organised sport,

14. A trend seems to be that physical activity happens more and more in constructed facilities, and if possible, indoors, 
15. Individual perception of body in physical activity is very important to motivation for, and intention to, participate.

\section{Some research data on physical and sportive activity of Czech population}

In the Czech context, a higher level of decentralization and competent transmission in regional autonomy is needed. This would improve the chances and amenities for regular whole-life physical activities, material outfit, preparation of specialists, the realization of long-term education among coaches and instructors, and fundamentally increasing state financial support for mass sport. Sport for all must be an integral part of the future relationship of sport to health, education and socialization. Recommendations to sport organizations for the systematic promotion of physical activities needs the full support of local, regional and national public authorities:

1. To develop a membership strategy to include physically passive persons in sportive activities,

2. To specify the profile target of sport clubs in accordance with a focus on elite and competitive sport or recreational leisure sport activities,

3. To improve standards for coaches and trainers aiming for an inclusive social and pedagogical climate,

4. To accent natural outdoor activities as grassroots centres for mass involvement in physical activities,

5. To ensure and enable high educational and pedagogical standards for voluntary and (semi) professional staff in sport clubs.

Although prospects for the revitalization of a physically active society are questionable, we are obliged to change or modify a long-standing resistance to exercise among our contemporaries. Postindustrial (or) post-modern society is characterized by an involvement in momentary short-term experience, adrenaline enjoyment, refusing traditional and long-term values, and is not good place or cultural context for a transformation to physical activity both at the societal and individual level. Such transformation will be filled with false starts and obstacles, facing innumerable barriers. These barriers (except, in general, an inborn individual laziness and indolence) range from political and legislative opposition to struggles for limited resources with other health concerns and media indifference to social explanations for our physical activity problems. Public policy makers have not paid sufficient attention to public and health preventive medicine and healthy lifestyles. We live in a situation where most people agree that healthy lifestyles are a fundamental good for individuals and society. But a sedentary lifestyle also imposes many other subjects, costs and negative impacts on people not directly engaged in risky health behaviours. Strong smoking, alcoholism or even drug addiction within the context of a sedentary lifestyle of one member of a family can induce emotional stress on the rest of the family, or may cause individual financial hardship related to the loss of a job or overwhelming medical costs. From a strictly economical point of view, sedentary, unhealthy lifestyles cost billions in health care and lost wages, and are contributing to an economic drain on society as a whole. Another problem is related to the question of how far the national physical activity agenda can go in regulating personal behaviour: people do not want to be told what to eat, what to drink, and how much to exercise. Anyway, our chance to achieve a physically active society could be improved if we can transform the challenges of truly healthy lifestyles available to all members of society, or at least for most part of society.

Physical activity is a complex behaviour. Any activity can be described in terms such as intensity, frequency and duration, and these dimensions must be considered. An assessment methodology should also consider inactivity, such as time spent sitting. Physical activity can be related to work, transportation, home and leisure time. The activities at either of these domains may have specific health consequences, and advanced monitoring should also consider these. To present the most important results of existing research data related to physical inactivity, it is possible to conclude (Frömel, Bauman et al. 2006): 
1. Growing age of population (both men and women) decreases the number of weekdays and the volume of time devoted to physical activity,

2. Men in general are more involved in physical activties compared to women,

3. Growing age decreases existing differences in the intensity of physical activity between men and women,

4. Medium level of physical activity and walking is distributed in age groups and gender groups relatively evenly,

5. Walking is the most frequent form of physical activity in the Czech population,

6. Regular monitoring of the level and tendencies of physical activity of a population is an integral part of monitoring the health situation and lifestyle of a population.

Relevant recommendations regarding physical activities from the aforemmentioned research highlight:

1. More opportunities for active sportive activities for older populations of men and women,

2. To prepare and to realize self-contained programs for active recreational sport for all groups of a population,

3. Within school, teaching physical education contributes to a long-life interest in active physical activities,

4. Support in general walking and active transport as the most natural form of physical activity.

\section{Physical activity versus built environment with perspective of PREVOB Project}

In order to assess the extent of development and implementation of selected policy areas on dietary intake, physical activity level and obesity throughout Europe, health researchers, physical activity managers, and decision-makers are searching for a common methodology. Between the autumn of 2008 and the spring of 2009, thanks to support of WHO, a pilot project was tested in five European countries chosen to represent the five sub-regions of Europe, namely Bosnia and Herzegovina, the Czech Republic, France, Latvia and Turkey. Moreover, sub-regional working groups made up of stakeholders and experts have been organised to review the results of the pilot tests and discuss the relevance and applicability of the Policy Analysis tool within their sub-region. Project no. 044291 Prevention of Obesity in Europe - Consortium of the prevention of obesity through effective nutrition and physical activity actions - EURO-PREVOB (Derflerová-Brázdová et al. 2010).

EURO-PREVOB Project tested relevant hypotheses and summarized important data regarding built environment in the context of chances and limitations for mass physical/sportive activities and active transport (Sekot 2010):

1. Active participants and practical users of cycle lines. Most of them are recruited from social strata characterized by interest in healthy and active lifestyles incorporating regular leisure physical/sport activities. It would be very useful to identify a more detailed structure of cycle lines with respect to the intensity of physical/sportive activities. It is supposed that at least two fundamentals categories of cycle lines users exist:

a) regular users involved in periodic physical/sportive activities as a part of leisure in the context of everyday life,

b) occasional or provisionally "would sportsmen" involved in cycling, mostly as a part of personal image, practice cycling predominantly as a social activity without deeper rooting in value orientation containing regular physical/sportive activities as an integral whole-life part of everyday life.

A specific feature of the "cycle lines scene" in the Czech Republic calls attention to the growing presence of roller skating, which sometimes and in some routes exceed half of given participants. It reflects on the one hand the high dynamics of the popularity of roller-skating and on the other hand the poor level of official and legal regulation or conception of "game rules" of the cycle lines. Unfortunately there are negative impacts for participants: collisions, injuries, interpersonal conflicts. 
Another typical aspect of monitored cycle paths is their "leisure" nature. Cycle paths are mostly located in suburban or outskirts areas connecting recreational points rather than the location of everyday practical activities. As a consequence, it is not practical to use cycle paths to travel to work, to deal with civic affairs or go shopping. Cycle paths are mostly used in a one-sided way: leisure activities. Good physical and psychical shape, well-being, or personal image are the most frequent reasons for being part of the cycle lanes scene; a practical way of everyday transport is only a marginal motive for mass cycling in the Czech Republic.

2. Public open spaces as a part of built environment are - from the perspective of their quantity as well from the point of view of their quality - dependent on the fundamental character of given settings. Social, cultural and economical features of selected areas play very important roles and are also a significant precondition of the appearance of public parks and public playgrounds. Wealthier neighbourhoods provide more parks and playgrounds than socially, culturally and economically less booming, poor, disadvantaged or neglected boroughs (or even ghettos). The most striking dividing lines or contrasts are visible and tangible between ethnic ghettos (gypsy) on the one side, and prestigious boroughs on the other. With reference to public parks, their occurrence as well their quality (maintenance, neatness, service, safety) is incomparably higher in healthy boroughs than the analogous situation in poor neighbourhoods. In given situations there exists another feature: in top prestigious "high" society neighbourhoods, inhabited with people living in private family houses, villas or residences, the existing public parks are not as visited and popular - local people prefer to stay in the luxury of their own houses and gardens, or to visit "specific" leisure and recreational facilities in different or distant places. Most popular are the public parks in good sustentative "middle" class neighbourhoods provided in most cases with playgrounds for children. On the contrary, public parks in socially neglected parts of the city are rather small, badly maintained, dirty and insecure. The common problems found in most public parks in all neighbourhoods are dog excrement and vandalism.

3. Playgrounds - from the perspective of their existence and their quality - vary as a matter of principle - in accordance with the aforementioned situations in public parks: higher quality exists in wealthier neighbourhoods; neglect and misery are provided in poor neighbourhoods. Specifically, with aspect to the aforementioned ones, is a high level of vandalism. In some public playgrounds interested people are allowed enter and use public playgrounds only in presence of commissioned person delegated by local municipality! Another negative aspect of monitored public playgrounds is the absence of publicly available sportive and fitness equipment and facilities, presumably as a consequence of the apprehension of vandalism. Public playgrounds are in fact having to defend against a growing incidence of commercial fitness centres. Such a situation reflects the deepening gap between different social strata (and quintiles), with a negative impact on the quality of life and structure of leisure of socially lower categories. The striking existence of vandalism, as well as a diffusion of lower social strata into higher quality public parks and playgrounds, result in generally poor quality public open spaces in researched localities - public parks and public playgrounds.

4. The existence and quality of public transport stops reflects the quality of public transport in general, and the relevant local social, cultural and economic situations as well. It is not primarily the existence of public transport stops, but their quality that reflects the nature of given neighbourhoods. Quality, ergo the comfort, cosiness, neatness, non-desolated, and safeness of public transport stops, is supposed to be higher in healthier, better sustentative and more secure neighbourhoods. Transport stops are secure shelters for passengers waiting for their bus, trolley bus or tram. Smoking is strongly forbidden on tram platforms and transport stops. Sometimes, and mostly in center of the city, the welcomed appeal for care health and the fight against obesity is placed in the transport stops: "Presently the best way to improve your shape is to go to the next transport stop by walking". 
The quality (but not directly the existence) of public transport stops in socially disadvantaged city districts is mostly reduced in quality and regards to comfort and security as a consequence of vandalism, deficient maintenance and the destructive presence of local youth gangs and socially nonadaptable individuals. Local youth also use (disuse) public indoor or roofed transport stops as a place for to coming together or as a shelter in bad weather. But in general, the quality of transport stops is first and foremost given by the nature of passengers (mostly lower social strata) with no direct relation to the nature of the relevant neighbourhoods.

5. Frequency of traffic volume above all reflects the dynamic factor for the general possession of private and business cars in the Czech Republic as well as the relative mass use of cars for everyday transport to work and for shopping. Suburban areas are strongly affected by truck transport and commute workers; housing estates are affected by mass lodging typical for the block of council houses which are mostly in the vicinity of busy highways and supermarkets. To the contrary, housing estates of higher social classes are mostly far - and prevented - from busy and noisy roads, factories, business points and hypermarkets. The sparse populations in private family house neighbourhoods benefit from low and quiet traffic volume, whilst the high concentration of populations using cars and traffic transport in socially low housing estates and in the centre of the city are affected by busy, noisy, and polluting transport and traffic volume. But it must be taken in account that the phenomenon of traffic volume is a multi-dimensional one and as such is not linearly shaped with immediate social cultural settings.

It is more than evident that built environment plays an important and growing role in the quality and attractiveness of neighbourhoods, including chances and limitations for regular and publically accessible healthy sportive/physical activities. To have or not to have a "good neighbourhood" is the fact gaining strength in the post-communist Czech Republic too. Growing social and economic difference in Czech society increases aspects of social inclusion and exclusion, and a "good address or bad address" is important attribute for the attractiveness/unattractiveness of built environment. This factor is given more attention during the personal decision-making processes than the quality and aesthetic attractiveness of given apartment or house. It works on the level of prestige of a "private address" as well in a "business address". Despite of the last decade of "unrestrained capitalism", more attention and emphasis is being focused not only on the level of attractiveness of a new house, but also on the quality of the general built environment: living conditions, quality of urbanism, stillness, transport accessibility, security, social structure, existence of schools, public facilities, shopping opportunities, level of air pollution, contact with green nature, and the existence of sportive facilities. But the built environment in a given territory is not socially and culturally structured enough to reflect the visible and tangible attributes of the sociologically structured levels of neighbourhoods.

The most critical policy area on physical/sportive activity is the fact that the development of a sedentary lifestyle is the result of a socialization process towards physical inactivity developed in youth and continued into adulthood. Social analysis of inactivity and patterns of sedentary living conclude that in the Czech Republic there is a very high level of prestige for sport and sportive activities in Czech society. But at the same time it confirmed a generally known fact that, while the significant part of the population has a positive attitude to physical sportive activities, this attitude is not realized in practical, personal everyday lives in the form of regular physical or sport activities. People in the Czech Republic, are in many respects permeated by the busy capitalist rhythm of a "post-transformed society" one-sidedly oriented at performance, success, popularity, money, societal admiration. In such a milieu, the endangered and problematic groups of the population are busy, stressed, and feel the lack of leisure and long hours of car driving and high technology associated with top businessman, managers and "workaholics". A similar experience is seen in socially deprived groups such as jobless people or ethnic minorities (mostly Gypsies) which lack the proper value orientation accenting healthy and sustainable style of life, absorbing healthy dietary habits, regular intentional physical exercising, and sportive and outdoor activities (Slepičková, Flemr 2007). 


\section{Conclusions}

To discuss the phenomenon of physical activity means to mention also the changing nature of lifestyles and leisure time activities that have adopted new forms, contents and meanings. The world of sport and physical activities is also changing all the time, change which can be seen in numerous new sport disciplines and activities which are chosen by a growing proportion of people. It could be expected that these changes would affect also the social situation and environment of physical activity:

1. The Czech situation must be prepared for specific situation of enthnical minorities (mostly Romany populations) reflected to the level of their attitude to physical and sportive activity. In traditional Romany culture the positive attitude to sport is derived from relevant value attitudes of the majority society. The mostly young generation of this minority appreciate sport in positive way, thanks to peers and school education. Despite such positive tendencies only $14 \%$ of gypsy youth are involved in regular sportive activities - mostly in football, jogging, biking, swimming and dancing (Hastrmanová, Houdek 2007). Also, the 9-11 year-old pupils of practical elementary schools are not properly and proportionally involved in extracurricular movement activities. Just $19 \%$ of them participate in organized physical activities, compared with $55 \%$ of children from ordinary elementary schools.

2. Presented structure of attitudes to sport activities reflect given social and cultural situations in the Czech post-reformation setting. People are not consistent enough to overcome their laziness, are too busy, too involved in everyday economic problems, not properly appreciated and enjoying the refreshing impact of regular physical activity compensating for the many-sided stress of societal life. But we also take into account the fact that people are prone to declare an absence of leisure as substitutional reason. Relevant data reflects in the Czech population a growing tendency of passive attitudes to sport. Physical inactivity is justified with absence of leisure, absence of meaningful motivation, and an existence of healthy problems. $40 \%$ of "programmatic physically inactive" acknowledge a substantial aversion to physical activity, $28.5 \%$ declare a health problem and $20 \%$ an absence of leisure. Only marginally mentioned is an absence of sport facilities and financial obstacles (Slepička, Slepičková 2002).

3. To present the most important results and informations on tendencies in the field of physical activities means to conclude that the growing age of population (both men and women) decreases the number of weekdays and the volume of time devoted to physical activity. Men in general are more involved in physical activities and active transport (cycling, walking) compared to women.

4. Nowadays physical education is defined as the process aimed at preparing children and young people for participation in physical culture (tourism, recreation, sport). It is also understood as the foundation of physical culture. Physical education in its humanistic version is understood as "an education of man for the care of the body". Humanistic aspects relating to physical education accent intentional activity aimed at forming positive attitudes towards the body, familiarizing a person with the world of physical culture consisting of shaping attitudes towards the body and the values of physical culture, an education for the values of the healthy body, an education of the personality for the care of the body, preparing children and young people for taking responsibility for health, fitness and the beauty of the body after competing their education.

5. Social environments consist of the nonphysical products of human interaction, which include the ideas and values shared by members of a particular group as well as when they come together to participate. The synergistic roles of physical and social environments affect participation in physical activity. Resulting behavioural settings can promote physical activity when they provide the physical space (e.g. sport facilities, health clubs, bicycle paths, swimming pools) along with the social resources that we draw upon to interact with others in community-policing programs. 
6. The phenomenon of physical/sportive activity is a many-sided phenomenon connected with the concept of a healthy lifestyle. Life style behaviours are in general significantly determined by social status, by professional position, by amounts of money and quantity of property. Those who have the means may choose to be physically active; those lacking financial resources cannot freely choose to be involved in regular sportive activities. Unhealthy behaviours, including sedentary lifestyles, are influenced by people's position within social groups and broad social forces in the general society. But decisions about whether to adopt a healthy lifestyle reflect personal attitudes and value preferences and thereby include aspects of personal choice. But factual personal choice has many preconditions with the social position and cultural quality of people and with access to resources of the full range of choices regarding sportive activities. We can conclude: Healthy lifestyles are patterns of voluntary behaviours based on choices from options that are available to people according to their life situations. In developed post-industrial countries, the members of the upper- and middle-class, by way of active lifestyles, mostly reflect their valued self identity by accenting a balanced share of intellectual and physical activities. It is a tendency to evaluate good health as a personal value to be sought and cultivated for one's own benefit, such as experiencing increased vitality and enjoyment of life. Lower-class individuals, with reference to the nature of their work activities and income, are less optimistic to avoid poor health and thus are less apt to participate in systematic healthpromoting activity. Anyway, members of lower socioeconomic positions experience poorer health and higher rates of disease when compared with more privileged social groups.

7. The phenomenon of physical activity and sport is closely related to urbanisation of sports facilities. Rapid housing and industrial development is resulting in numerous urban-architectural and sociological issues. Sport facilities planning, creating, developing and managing should be considered to be one of the strategic points in public administration on both the local and state levels (Flemr 2007). All experts agree that it is necessary to promote sport. In this sense they think that investment in sport will provide important returns derived from those important benefits to health. Such a fact is an important argument for practical, social and budgetary importance that sport has (or should have) for individuals and for society as a whole.

Even the preliminary results of this research data and pilot study imply that individual authorities, localities and groups of people attach a diametrically different importance to sport, physical and sportive activities. A large difference is already visible in the managing of sport and sporting activities within the different levels of sport and different demographic strata of the population. In this context alone we could conclude that the population has internalized the benefits of practice of sport, but still has not internalized the habit of practicing sport, because it is conditioned differently within each group of the population. The most critical policy area on physical/sportive activity is the fact of sedentary nature of contemporary society: very high levels of prestige for sport and sportive activities in Czech society is incompatible with very low levels of practical, regular physical or sport activities. In the future, sociological research might study the motivational structure of population in physical/sportive activities with reference to age, sex, social status and another relevant demographical criterions.

\section{REFERENCES}

Allender, S., Cowburn, G., Foster, Ch. (2006). Understanding participation in sport and physical activity among children and adults: a review of qualitative studies. Health Education Research: Theory and Practice, vol. 21, 6, 826-835.

Andersen, L. B. et al. (2007). Physical activity and physical fitness in relation to cardiovascular disease in children. Obesity in Europe. Young People's Physical Activity and Sedentary Lifestyles. Berlin, Oxford: Peter Lang. 
Derflerová-Brázdová, Z., Schwanhauser, K., Sekot, A., Hruška, D., Sebera, M. (2010). EURO-PREVOB: dílčí zpráva o spolupráci Masarykovy univerzity jako zástupce České republiky na projektu 6. rámcového programu č. 044291. Zdraví, 1, 1-7.

Evans, J. (2003). Physical education and health: A polemic or "let them eat cake!" European Physical Education Review, 9, 87-101.

Flemr, L. (2007). Podmínky pro aktivní životní styl dětí perspektivou pedagogů tělesné výchovy. Aktuální otázky sociologie sportu. Praha: Karlova univerzit

Formánková, S. (1998). Některé oblasti longitudinálního výzkumu zájmu žáků o pohybovou aktivitu. Celostátní vědecká konference s mezinárodní úèastí v oboru kinantropologie. Olomouc: Hanex.

Fořt, P. (2004). Stop dětské obezitě. Praha: Ikar.

Frömel, K. et al. (2004). Physical activity of men and women 18 to 55 years of age in Czech Republic. In F. Vaverka (Ed.), Movement and Health (pp. 169-173). Olomouc: Univerzita Palackého.

Frömel, K., Bauman, A. et al. (2006). Intenzita a objem pohybové aktivity 15-69 leté populace České republiky. Česká kinantropologie, vol. 10, č. 1, 13-27.

Hlúbik, P. et al. (2000). Prevalence of obesity in selected subpopulations in the Czech Republic. Sborník lékařský, 1, 59-65.

Kovář, R. (2002). Tělesná aktivita, tělesná zdatnost a zdraví. Česká kin antropologie, roč. 6, č. 1, 49-54.

McElroy, M. (2002). A Social Analysis of Inactivity. Champaign, IL: Human Kinetics.

Project no. 044291. Prevention of Obesity in Europe - Consortium of the prevention of obesity through effective nutrition and physical activity actions - EURO-PREVOB.

Rychtecký, A. (2007). Active Lifestyles of Young People - Benefits and Outcomes. Obesity in Europe. Young People's Physical Activity and Sedentary Lifestyles (pp. 199-218). Berlin, Oxford: Peter Lang.

Rýgl, P. (2006). Tvorba školních vzdělávacích programů pro oblast tělesné výchovy na základní škole. Česká kinantropologie, vol. 10, č. 2, 29-45.

Sallis, J. F., Owen, N. (1999). Physical Activity and Behavioral Medicine. California: Sage.

Sanchez, D. M., Estrada, E. M. et al. (2009). Sport, Health and Quality of Life. Barcelona: Obra Social Fundación "la Caixa".

Sekot, A. (2006). Socoilogie sportu. Brno: Paido a Masarykova univerzita.

Sekot, A. (2008). Physical Activity Versus Obesity. Educatio Artis Gymnasticale, roč. 3, č. 3, 51-72.

Sekot, A., Brázdová, Z. (2008). Physical Activity and Nutrition as a Social Factors Influencing the Epidemic of Obesity. Studia Sportiva, roč. 2, č. 1, 112-125.

Sekot, A. (2010). Determinanty nadváhy a obezity: pohybová aktivita a materiální prostředí. Zdraví, 1, 24-32.

Slepička, P., Slepičková, I. (2002). Sport z pohledu české společnosti. Česká kinantropologie, 1, 7-23.

Slepičková, I., Staněk, M. (2007). The impact of public administration reform on sport policy in Czech Republic. Local Sport in Europe. $4^{\text {th }}$ EASS Conference Proceedings.

Staněk, M., Flemr, L. (2007). The role of local authorities of Czech cities in support of sport: A case studyof the capital city of Prague. Local Sport in Europe. $4^{\text {th }}$ EASS Conference Proceedings.

Šeráková, H. (2007). Present views on obesity and overweight in common population of children and adults. School and Health. Brno: Masarykova univerzita a Paido.

United States Department of Health and Human Services (1996). Physical activity and health: a report of the Surgeon General. Atlanta: USDHHS.

Vaverka, F. (Ed) (2004). Movement and Health. $3^{\text {rd }}$ International Conference Movement and Health Proceedings. Olomouc: Univerzita Palackého.

\section{AUTHOR'S ADDRESS:}

Aleš Sekot

Masaryk University, Faculty of Sport Studies

Kamenice 5, 62500 Czech Republic

Email:sekot@fsps.muni.cz 